\title{
COMPARISON of GRAVITY, EM and DC-MULTI-ELECTRODE MEASUREMENTS CARRIED OUT ALONG TWO PROFILES.
}

\author{
F. Kohlbeck ${ }^{1}$, A. Marcuello ${ }^{3}$, J. Pous ${ }^{3}$, P. Queralt ${ }^{2}$, R. Supper ${ }^{3}$, T. Yelkency ${ }^{1}$
}

Gravimetric, DC-multi-electrode, Electromagnetic EM34 and VLF measurements were carried out on two profiles. One profile (linel, direction WE, length $=3.8 \mathrm{~km}$ ) leaded downward a hill into a flat area, the other one (line 2, direction $\mathrm{SN}$, length $=1.2 \mathrm{~km}$ ) passed the first one at its W-end and followed a road of about constant altitude. Near the downhill end of the first line a drilling was located. At this side the measurements could also be compared with older seismic data. The top layer consists of gravel sand and clay. The basement is formed by schist and limestones of high porosity. The sands and clays of the lower part of the profile are water saturated, where as the gravels of the higher parts are dry.

\section{MEASUREMENTS}

Measurements were taken using $10 \mathrm{~m}, 20 \mathrm{~m}$ and $40 \mathrm{~m}$ coil distance, horizontal and vertical dipole with the EM 34 instrument at $10 \mathrm{~m}$ and $20 \mathrm{~m}$ distances between measuring points. A special technique was introduced to get the coils rapidly coplanar (horizontal) with vertical dipole arrangement: each of the two coils was suspended with three strings of equal length on a stick. If the stick is held vertical the coil is remains horizontal at the height of the eyes of the user. Taking the coil with both hands one can easily move it for and back without touching the stick. Even one handed placement of the coil is possible. The stick changes its inclination to the surface during moving of the coil, but remains fixed at his foot point. Independent from the movement for and back one can also change the inclination of the coil with respect to the earth. With this technique one can correct the position and the inclination of the coil for accurate measurements within a time comparable to horizontal dipole measurements. The gravity measurements followed every $50 \mathrm{~m}$. The instrument heights have been evaluated by geodetic methods with an accuracy better than $2 \mathrm{~cm}$. Two DC multi-electrode measurements were carried out with $15 \mathrm{~m}$ electrode distance and 80 electrodes each. The maximum profile extension of $1200 \mathrm{~m}$ allowed for a penetration of up to $190 \mathrm{~m}$ of depth.

\section{EFFECT of DISTURBANCES on EM-MEASUREMENTS}

EM measurements are carried out very rapidly compared to other measurements, but are strongly affected by disturbing fields in some cases. At locations not well known testing with special instruments for locating telephone lines and mains is the usual practice for avoiding wrong interpretations. However there can be other sources more, effecting the accuracy of the measurements. Repeating the measurements at different times, shifting the location for a small amount and changing the direction (with two coil system) are means to control the validity of the measurements.

Line 1 passed a town and leaded along mains $E$ of the town. VLF measurements repeated on the same location in this part of the line showed inconsistent values. For that reason EM and VLF measurements were not taken in this region. VLF measurements along line 2 taken at different days are shown in Fig. 1: Where as the real components agree well for both days the

\footnotetext{
${ }^{1}$ Tech. Univ. Vienna, Gusshausstrasse 27-29, A1040 Vienna.

${ }^{2}$ University Barcelona

${ }^{3}$ Geological Survey Austria, Tongasse 10, A1030 Vienna.
} 
imaginary components differ considerably. Good agreement in shape can be observed also for the Im-component in the middle part of the diagram apart from a vertical shift of about 20 units.

EM measurements taken at different coil separations and dipole directions are shown on Fig. 2 Two prominent peaks visible at $60 \mathrm{~m}$ and $160 \mathrm{~m}$ horizontal distance on the vertical dipole curves can also be observed with the horizontal dipole configuration but with considerable smaller amplitude. This peaks were not observed with the VLF instrument. The non geological nature of this peaks can be concluded from a profile (line 4) made at $40 \mathrm{~m}$ distance parallel to line 2. The measurements on that line showed no peaks and the mean value of the apparent resistivity was considerably lower (lowest values in Fig.2, distances from 0 to $160 \mathrm{~m}$ ). The low values were confirmed by measurements with the alignment of the arrangement perpendicular to line 2 located between line 2 and line 4 . However, contrary to this observation, no telephone line or main is known on line 2. The interpreted section of multi-electrode measurements on line 2 showed average high resistivity values of about $500 \mathrm{Ohmm}(2 \mathrm{mS} / \mathrm{m}$ conductivity) for depth up to $30 \mathrm{~m}$ with some locations of lower resistivity at shallower depth. Among the EM measurements such low values of conductivity were solely obtained with the vertical dipole configuration at $40 \mathrm{~m}$ coil separation in the northern part of the section. The average of all EM-measurements is about $5 \mathrm{mS} / \mathrm{m}$.

\section{RESULTS - GRAVITY and DC}

Bouguer-anomalies and interpreted depth obtained from the gravity measurements along line 1 and line 2 are drawn on Fig.3, and Fig. 4 respectively. The horizontal scale for both lines is differently, where as the vertical scales have been taken equal for better comparison. The interpretation was based on the assumption of the existence of two materials (sediment and basement) and an average crustal density of $2.67 \mathrm{~g} / \mathrm{cm}^{3}$. Further confirmation was inferred by a drilling at station $2450 \mathrm{~m}$ where competent rock was found at $190 \mathrm{~m}$ of depth. Line 1 shows a distinct edge of the basement at $1.6 \mathrm{~km}$ on the local horizontal axis leading down from an approximatively horizontal level at $50 \mathrm{~m}$ of depth to more than $300 \mathrm{~m}$ with the end of the slope not observed on the profile.

The multielectrode measurements on linel were located between station $850 \mathrm{~m}$ and $2050 \mathrm{~m}$. The measurements have been interpreted by Loke and Barker's method. The interpreted section calculated from Wenner pseudosections is drawn on Fig.5. Comparison with the gravity measurements leads to a border between basement and sediment at the $100 \mathrm{Ohmm}$ line.

The sudden onset of the inclination of the slope of the basement observed with the gravity measurements can also be observed on the electric profile. For comparison the electric interpretation is also drawn into the gravity profile of Fig. 3. One recognises, that the surface of the basement is found to be shifted about $100 \mathrm{~m}$ to $\mathrm{W}$ and somewhat deeper with the electric interpretation. The old refraction seismic interpretation did not fit the drilling results and could be reinterpreted with much better accuracy on basis of the gravity interpretation.

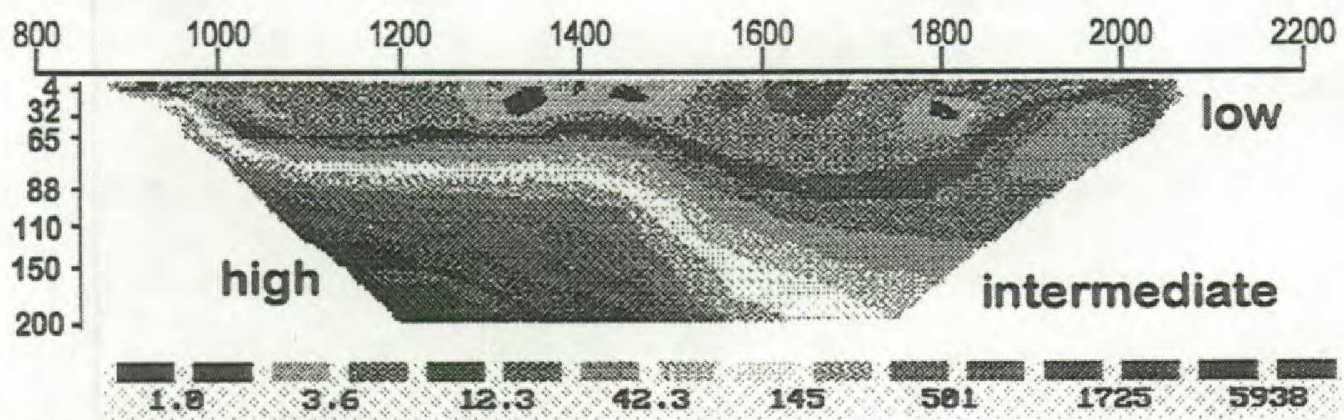

Fig. 5: Interpreted depth section of DC measurements. Resistivites along line 1 

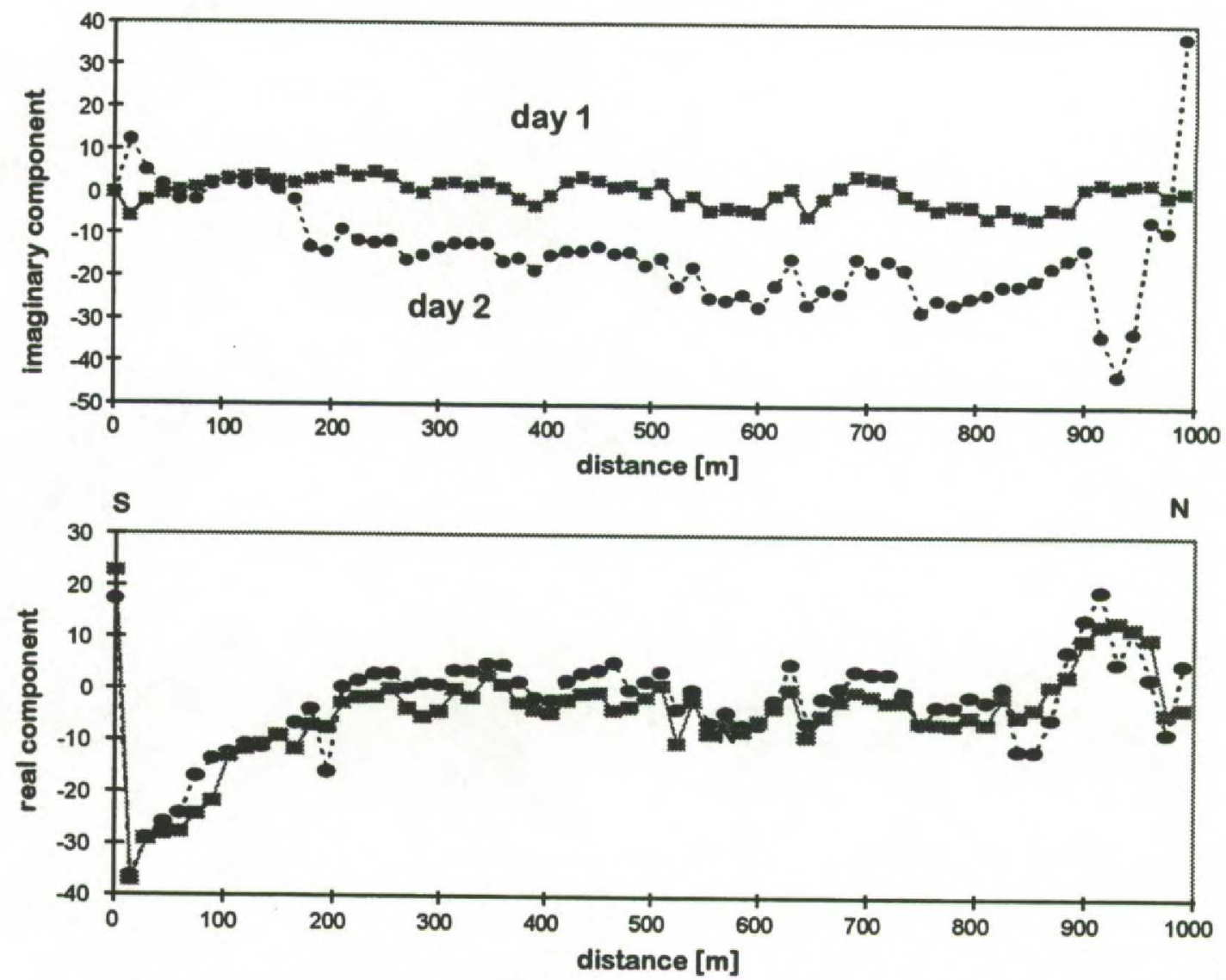

Fig.1: VLF response measured on two different days along line 2

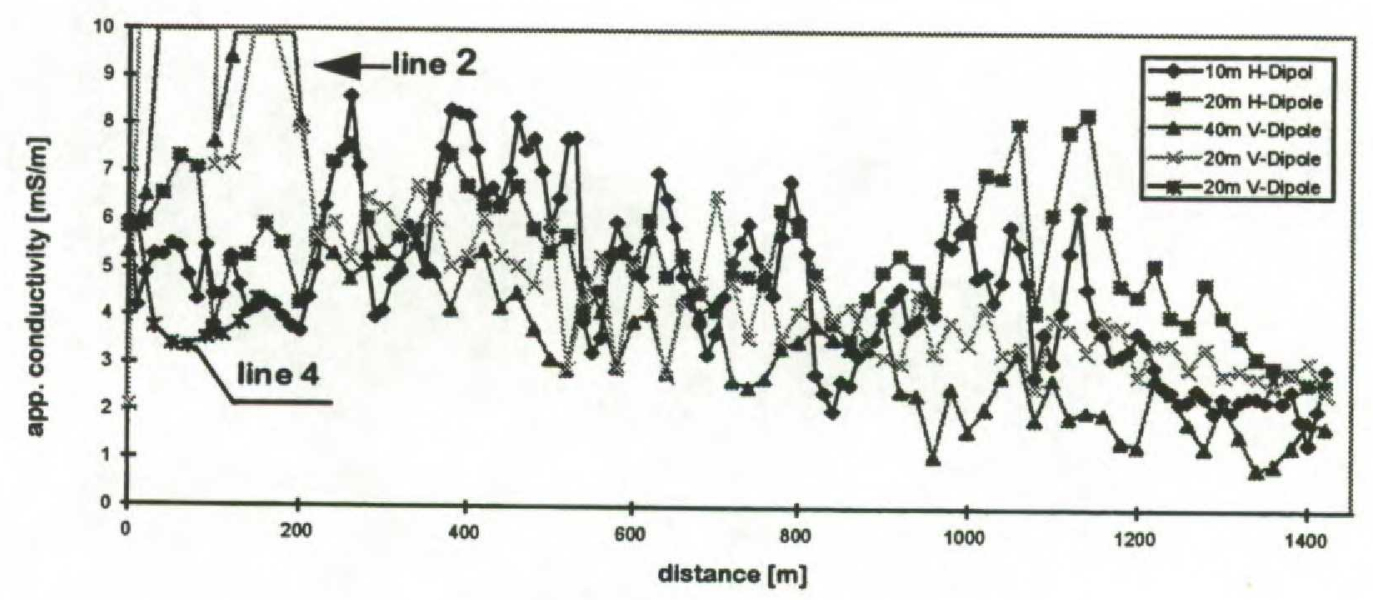

Fig. 2: EM34 response along line 2 and line 4 (20m V-dipole only) 


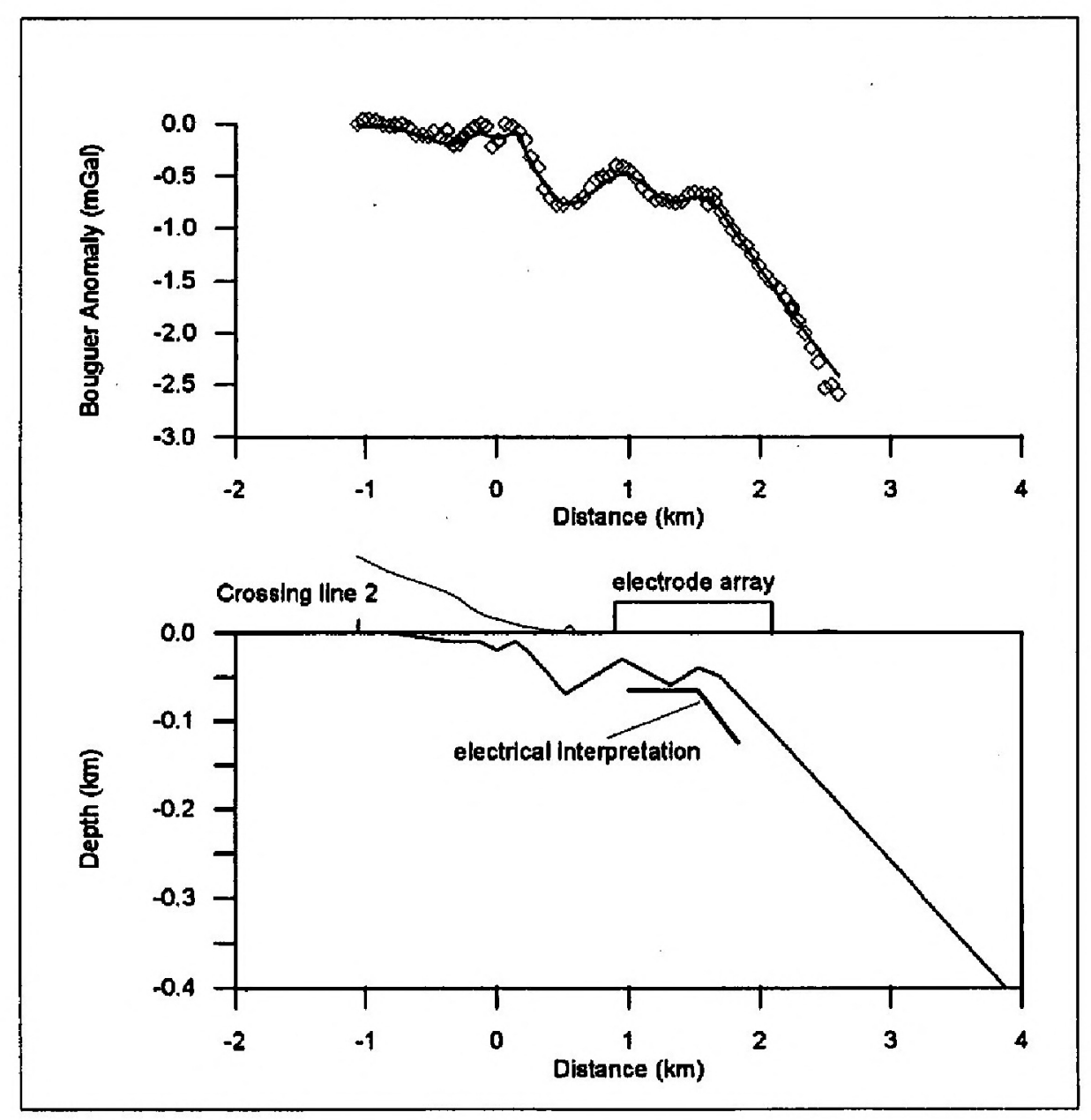

Fig. 3: Line 1. Bouguer anomalies and interpreted depth to basement.

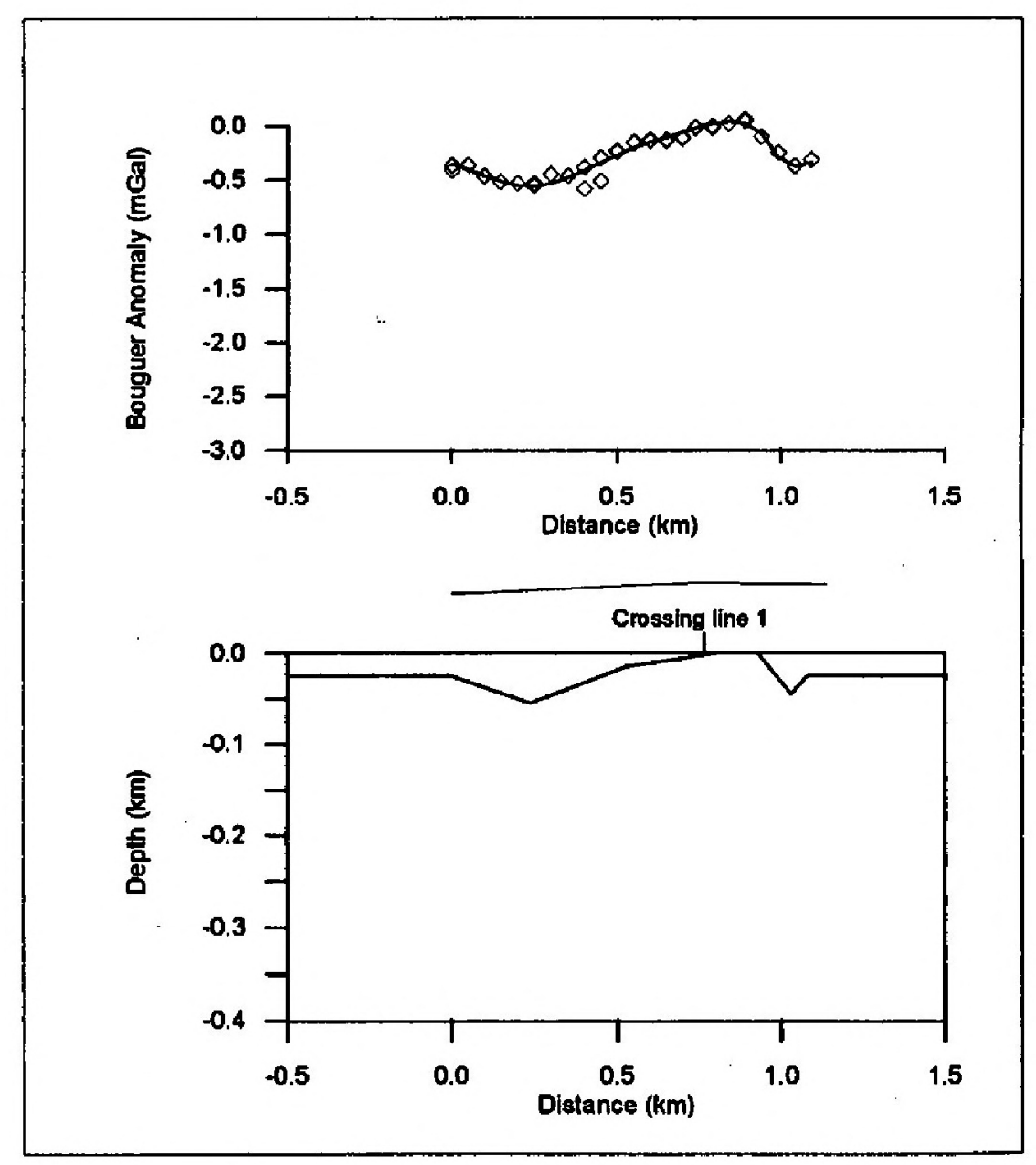

Fig. 4: Line 2. Gravity profile 